\title{
LEITURA ASCÉTICA DA LITERATURA MODERNA: REALIZAÇÃO INDIVIDUAL EM WALTER BENJAMIN
}

ASCETIC READING OF THE MODERN LITERATURE: INDIVIDUAL ACHIEVEMENT IN WALTER BENJAMIN

Eduardo Guerreiro Brito Losso

UFRRJ

Nova Iguaçu, RJ, Brasil

Palavras-chave: leitura; prática de si; ascese; literatura moderna.
Keywords: reading; practice of self; asceticism; modern literature.

Palabras clave: lectura, práctica de sí, ascetismo, literatura moderna.

* (PESSOA, Fernando. Obra poética. Rio de Janeiro: Nova Aguilar, 1997: 388.)

* (BENJAMIN, Walter. Magia e técnica, arte e política: ensaios sobre literatura e história da cultura. São Paulo: Brasiliense, 1994: 226.)

\section{Resumo}

Admitindo que haja dependência mútua entre realização coletiva e individual no pensamento de Walter Benjamin, o artigo extrai de seus ensaios como que sua leitura da literatura moderna propóe uma prática de si que faz da escrita uma espécie de exercício espiritual moderno: uma ascese da leitura e escrita.

\section{Abstract}

Admitting that there is mutual dependence between individual and collective achievement in the thought of Walter Benjamin, the article draws from his essays how your reading of modern literature proposes a practice of self that makes the writing a kind of modern spiritual exercise: a asceticism of reading and writing.

\begin{abstract}
Resumen
Admitiendo que existe una dependencia mutua entre los logros individuales y colectivos en los escritos de Walter Benjamin, el artículo extrae de sus ensayos como que la lectura de la literatura moderna propone una práctica de si que hace de la escritura una especie de ejercicio espiritual moderno: una ascesis de la lectura y escritura.
\end{abstract}

\section{Introdução}

Ah, quem escreverá a história do que poderia ter sido?

Será essa, se alguém a escrever, A verdadeira história da Humanidade.*

Se Walter Benjamin, no momento da escrita de Teses sobre o conceito da história, tivesse lido essa estrofe do Álvaro de Campos de Fernando Pessoa, possivelmente seria tentado a utilizá-la como epígrafe. $\mathrm{E}$ as teses complementariam a provocação pessoana respondendo que o escritor dessa "história do que poderia ter sido" é o historiador comprometido com a "tradição dos oprimidos", 
aquele que a lê como a série de vitórias das classes dominantes e derrotas dos dominados. Sua reescrita da história retiraria do passado não só a verdade da derrota fundamental da emancipação, mas também os sonhos utópicos contidos nas "coisas espirituais", que "questionarão sempre cada vitória dos dominadores".* A verdadeira história da humanidade seria feita das vitórias que foram perdidas. Pessoa e Benjamin, assim como nós estamos todos produzindo a escrita e a leitura de uma história que ansiamos para que um dia se realize.

Para que isso seja possível, contudo, é preciso que algo dessa história seja escrita em nossa vida, seja realizada, relativamente e na medida do possível, em nosso corpo. Embora a realidade do sistema social de dominação esteja a todo instante, e das mais variadas maneiras, afastando-nos da felicidade, o apelo que as derrotas do passado dirigem a nós nos concedem a "frágil força messiânica”* para realizarmos algo de suas aspirações em nosso tempo presente. Contudo, nosso espaço de manobra para obter algo coletivamente é tão exíguo quanto o das gerações passadas.

Logo, o sujeito pode realizar em si mesmo mais das aspirações coletivas do passado do que em uma sociedade dirigida pelo sistema. Resta saber, contudo, o que exatamente o sujeito pode fazer consigo mesmo, qual espaço e quanto dele lhe é concedido para agir e como ele reavivará a memória dos sofrimentos e aspirações do passado. Também nessa questão Fernando Pessoa, na pele do Bernardo Soares do Livro do desassossego, encontrou uma formulação preciosa: "Sofri em mim, comigo, as aspirações de todas as eras, e comigo passearam, à beira ouvida do mar, os desassossegos de todos os tempos".* Nesse momento de contemplação, Bernardo Soares está à beira-mar acolhendo a totalidade da história num momento de silêncio pessoal. Não é num estado de inquietude que melhor se pode refletir sobre os problemas da humanidade, senti-los, intuílos, antes, ao contrário, em momentos de serenidade, em interlúdios ou adagios, não em allegros. Foi com a mesma calma (mesmo em meio à fuga desesperada) que Benjamin, na tese II (uma das mais intrincadas), associou a "imagem da felicidade" que se encontra na memória do "curso de nossa existência" com o "índice misterioso" do passado que "impele à redenção".* Por mais direcionadas que as teses estejam à redenção coletiva, é o indivíduo que a incorpora "em sua existência vivida", ${ }^{*}$ isto é, as memórias individuais se conjugam com as coletivas, dão a elas a determinação de
* (Ibidem: 224.)

* (Ibidem: 223.)

* (PESSOA, Fernando. Livro do desassossego. Lisboa: Assírio \& Alvim, 2008: 114.)

* (BENJAMIN, Walter. Magia e técnica, arte e política: ensaios sobre literatura e história da cultura. São Paulo: Brasiliense, 1994: 222-223.)

* (Ibidem: 45.) 
* (BOCK, Wolfgang. Vom Blickwispern der Dinge: Sprache, Erinnerung und Ästhetik bei Walter Benjamin. Vorlesungen in Rio de Janeiro 2007. Würzburg: Königshausen \& Neumann, 2010: 37, 47.)

* (FOUCAULT, Michel. A hermenêutica do sujeito. São Paulo: Martins Fontes, 2006: 155-160.)

* (BENJAMIN, Walter. Magia e técnica, arte e política: ensaios sobre literatura e história da cultura. São Paulo: Brasiliense, 1994: 38; BENJAMIN, Walter. Gesamme/te Schriften II.1. Rolf Tiedemann e Hermann Schweppenhäuser (org.). Frankfurt: Suhrkamp, 1991: 313.)

* (PROUST, Marcel. À l'ombre des jeunes filles en fleurs (Première partie). Paris: Gallimard, 1961a: 9293.)

* (PROUST, Marcel. À l'ombre des jeunes filles en fleurs (Seconde partie). Paris: Gallimard, 1961b: 70.)

* (PROUST, Marcel. À l'ombre des jeunes filles en fleurs (Première partie). Paris: Gallimard, 1961a: 94.) uma experiência, assim como a experiência não existe sem a inserção do indivíduo na memória coletiva.*

Este artigo pretende destrinchar, por conseguinte, a especificidade prática de como o indivíduo pode trabalhar em si mesmo o clamor por justiça que o passado direciona a ele. Isso certamente levanta a questão de em que medida e até que ponto a busca pela felicidade individual não está, afinal de contas, respondendo às "aspiraçôes de todas as eras". Benjamin busca essa prática de si, para usar o conceito de Michel Foucault, ${ }^{*}$ na leitura interpretativa de grandes escritores modernos. É surpreendente a forma como a leitura da literatura de seu tempo se torna alimento essencial para uma busca pessoal que esclarece o anseio dos próprios escritores e contribui para a busca do leitor - atual, do século XXI - de seus ensaios. Leitura crítica é, aqui, exercício de si. Logo, a leitura crítica da literatura, a leitura da crítica como literatura ensaística e o exercício de transmissão de leituras torna-se a ocupação basilar de um exercício ascético moderno.

\section{Busca da felicidade}

Benjamin chama atenção, com ajuda de Cocteau, ao "cego, insensato, frenético" "desejo de felicidade" (Glückswille) de Proust, que "brilhava em seus olhos", e ainda que estes não fossem "felizes", "a felicidade estava presente neles, no sentido que a palavra tem no jogo ou no amor".* Verifica-se que quando a felicidade (bonheur) aparece na Recherche, está sempre ligada à paixão. $\mathrm{O}$ narrador de $\grave{A}$ sombra das moças em flor sonha com a alegria que só Gilberte poderia dar, e recebe com estupefação o milagre de ter em mãos a carta da amada a declarar sentir falta de sua presença. ${ }^{*}$ Em outro momento, ao avistar uma moça camponesa, reflete sobre o "caráter de novidade" "próprio da beleza e da felicidade", contraposto às sínteses generalizantes do pessimismo. Nas longas análises sobre o assunto, não escapa, todavia, que o "mistério" "disfarça muita vez aos olhos as catástrofes, quando se trata do amor". Em outras palavras, o prazer do encanto prenuncia o sofrimento maior, ainda que alivie a insatisfação constante. Proust sabe que tal sentimento introduz uma satisfação somente "para mudar de local o sofrimento" ("toute satisfaction qu'on lui donne ne fait généralement que déplacer la douleur").* 
Nesses dois exemplos, evidencia-se a imagem dialética benjaminiana dos olhos que, de infelizes, são tomados pela presença da felicidade. Acostumados à melancolia, sempre à espera do que não vem, relâmpagos de contentamento existem para abalar as bases da realidade, feita do hábito da dureza e da frágil e constante esperança, que deve ser assustada com a surpresa, em vez de saciada com a resposta. $\mathrm{O}$ romancista busca aquilo que não pode ser encontrado, aquilo que não se revela senão tomando de imprevisto, dominando olhos tristes de alegria - uma "trégua" (tréve) no sofrimento, dando a impressão de que é possível encontrar um alívio permanente.*

Proust sabe que não há cura para a própria "doença do desejo", para lembrar um conceito de Santo Agostinho.* "Mas a felicidade não pode ter lugar" ("Mais le bonheur ne peut jamais avoir lieu");* comparemos com o título do cap. XXV, livro XIV de $A$ cidade de Deus: "Na presente vida não se alcança felicidade".* Proust não deixa, entretanto, de empreender incansável e freneticamente uma busca sem fim. Tampouco sai de mãos vazias: retém o brilho nos olhos quando encanta-se com a beleza de um rosto "mais róseo que o céu" ("son visage était plus rose que le ciel'), , seja no passado distante do ocorrido, seja, principalmente, no momento de retomada escrita de sua rememoração.

A dialética da felicidade - a inevitabilidade da busca incessante, por mais convencidos que sejamos da impossibilidade intransponível - é, ela mesma, um vertiginoso labirinto. Benjamin recusa a saída mais fácil da resignação ascética burguesa, que leva a "considerar sua obra na velha e cômoda perspectiva da privação, do heroísmo, do ascetismo" ("unter der altbewährten, bequemen Perspektive der Entsagung, des Heroismus, der Askese zu betrachten"), "que uma grande realização é o fruto exclusivo do esforço, do sofrimento e da decepção" ("als eine große Leistung sei die Frucht von nichts als Mühen, Jammer und Enttäuschung")* Parece contraditório dizer que a privação é cômoda, mas a palavra "Entsagung" possui o sentido de renúncia resignada, e o emprego dado no contexto corresponde ao que podemos chamar de ascese burguesa, originada da ascese intramundana dos primeiros burgueses protestantes analisada por Max Weber, ${ }^{*}$ isto é, assemelha-se ao que chamamos vagamente de "puritanismo". Pessimismo e masoquismo cristãos são as distinções que impregnam a palavra ascetismo de um sentido depreciativo, frequente no uso que Benjamin dá a esse termo, e que não
* (Idem.)

* (AGOSTINHO, Santo. A cidade de Deus (contra os pagãos). Parte II. Petrópolis: Vozes, 1990: 137, 167.)

* (PROUST, Marcel. À l'ombre des jeunes filles en fleurs (Seconde partie). Paris: Gallimard, 1961b: 33.)

* (AGOSTINHO, Santo. A cidade de Deus (contra os pagãos). Parte II. Petrópolis: Vozes, 1990: 166-168.)

* (PROUST, Marcel. À l'ombre des jeunes filles en fleurs (Seconde partie). Paris: Gallimard, 1961b: 70. )

* (BENJAMIN, Walter. Magia e técnica, arte e política: ensaios sobre literatura e história da cultura. São Paulo: Brasiliense, 1994: 38; BENJAMIN, Walter. Gesammelte Schriften II.1. Rolf Tiedemann e Hermann Schweppenhäuser (org.). Frankfurt: Suhrkamp, 1991: 313.)

*(WEBER, Max. Gesammelte Aufsätze zur Religionssoziologie. Tübingen: J. C. B. Mohr (Paul Siebeck), 1986: 119.) 
* (BENJAMIN, Walter. Magia e técnica, arte e política: ensaios sobre literatura e história da cultura. São Paulo: Brasiliense, 1994: 39; BENJAMIN, Walter. Gesammelte Schriften II.1. Rolf Tiedemann e Hermann Schweppenhäuser (org.). Frankfurt: Suhrkamp, 1991: 313.)

* (BENJAMIN, Walter. Magia e técnica, arte e política: ensaios sobre literatura e história da cultura. São Paulo: Brasiliense, 1994: 39; BENJAMIN, Walter. Gesammelte Schriften II.1. Rolf Tiedemann e Hermann Schweppenhäuser (org.). Frankfurt: Suhrkamp, 1991: 313.)

* (BENJAMIN, Walter. Magia e técnica, arte e política: ensaios sobre literatura e história da cultura. São Paulo: Brasiliense, 1994: 45; BENJAMIN, Walter. Gesammelte Schriften II.1. Rolf Tiedemann e Hermann Schweppenhäuser (org.). Frankfurt: Suhrkamp, 1991: 320.) parece nada distante da crítica nietzschiana ao "ideal ascético" na Genealogia da Moral.

Para precisar o que entende por busca da felicidade antiascética, Benjamin distingue duas de suas formas: uma é hino, "o auge da beatitude", outra, elegia, "restauração da felicidade primeira", em que o eterno sempre aparece "mais uma vez". É a última, a proustiana, a que transforma a existência na floresta encantada da recordação. "Sacrificou a essa ideia, em sua vida, amigos e sociedade, e em sua obra, a ação, a unidade da pessoa, o fluxo da narrativa, o jogo da imaginação (Phantasie)."*

Supõe-se que a privação burguesa não possa conceber outro tipo de felicidade senão de uma forma épica grandiloquente, espalhafatosa, banal. Mesmo que haja uma estética própria do hino, o burguês só retira dela o imaginário da pompa em termos quantitativos: mede-se a beatitude até chegar a uma glória dos píncaros. Sua prática de vida não a tem como horizonte, e o lastro cristão a deixará para depois da morte, num paraíso inalcançável. Proust, ao contrário, transforma a existência ("das Dasein [...] verwandelt") do dia a dia numa eternidade do passado reencontrada no instante. Isso quer dizer que ele encontrou a fórmula para a vida se tornar fácil? Ao invés disso, lê-se que Proust sacrificou ("hat [...] geopfert") a normalidade de sua vida e a linearidade da narrativa de modo a se refugiar numa "floresta encantada da recordação" ("einen Bannwald der Erinnerung"). Benjamin insiste no fato de que, para adentrar-se na Bannwald, é preciso um "esforço frenético" ("frenetisches Studium"), cuja atividade não pode ser outra senão o "culto apaixonado da semelhança" ("sein passionierter Kultus der Ähnlichkeit").* Só mediante o estudo (Studium) apaixonado das correspondências - que Benjamin diz ter sido iniciado pelos românticos, compreendido por Baudelaire e posto em prática por Proust no primeiro plano da "vida vivida" ("die aber Proust (als Einziger) vermochte, in unserem gelebten Leben zum Vorschein zu bringen") - que é possível provar a eternidade do instante.*

A felicidade não faz os olhos brilharem nem com privações masoquistas, nem com flashes casuais do êxtase, mas somente com o "estudo" incansável do tempo vivido, isto é, do seu "universo dos entrecruzamentos" ("Universum der Verschränkung”). A matéria do estudo é o ponto de encontro entre o vivido e a faculdade de rememoração, o esforço frenético incide na riqueza labiríntica e contrapontística dos acontecimentos e de suas relações de semelhança. 
O que é imprescindível destacar é a diferença entre a privação ascética puritana e uma vida inteira "sacrificada" em prol do estudo apaixonado do tempo vivido, que abre o portal da floresta encantada dos entrecruzamentos. Benjamin quer apontar, na dialética da felicidade exercitada por uma existência insatisfeita, que o sacrifício incessante é recompensado, a felicidade dá as caras, até dá a graça de uma trégua do sofrimento, mas não resolve a doença de existir. $\mathrm{O}$ imenso esforço pessoal de uma investigação poética do vivido leva ao encantamento, ao contrário da privação burguesa, conformada com a impotência de sua banalidade. Porém não chega ao "tempo infinito", não encontra a eternidade absoluta, o auge da beatitude. A floresta encantada não substitui o desencantamento, antes, entrecruza-se com ele, a embriaguez (Rausch) imiscui-se na dor e é capaz de momentaneamente a vencer, mas não pode com e contra ela parar de lutar. Não é à toa que, mais adiante, Benjamin emprega pela segunda vez a palavra "Entsagung" defendendo que a fraqueza e o gênio de Proust encontram-se precisamente em sua "renúncia intelectual, o ceticismo experiente que ele opunha às coisas" ("die intellektuelle Entsagung, die erprobte Skepsis, die er den Dingen entgegenbrachte").*

Resistindo ao consolo romântico, não se deixando levar a pronunciar aquele "apesar de tudo" conclusivo, Proust é tão rigoroso no seu ceticismo existencial quanto um Beckett. Logo, é preciso privar-se da ilusão, não do prazer embriagador. A embriaguez de que fala Benjamin é lúcida, "é a tentativa interminável de galvanizar toda uma vida humana com o máximo de consciência” ("ist der unausgesetzte Versuch, ein ganzes Leben mit der höchsten Geistesgegenwart zu laden").* "Geistesgegenwart" não é a consciência oposta ao inconsciente, é presença de espírito, que não foge do sofrimento, ainda que Benjamin cite Jacques Rivière ponderando que Proust "morreu por ser estranho ao mundo" ("Er ist gestorben aus Weltfremdheit") e por "inexperiência” (Unerfahrenheit).* Não foge do mais difícil, não maquia o niilismo, mas, curiosamente, não encara a realidade empírica como o burguês de sucesso. A embriaguez é sim um estranhamento da realidade constituída, mas não é uma fuga da dor humana. Lá onde o burguês foge, o escritor moderno é herói, lá onde o burguês vence, ele é um fracasso.

Finalmente, Benjamin, depois de ter oposto a busca da felicidade de um cético estranho ao mundo ao ascetismo burguês e cristão, ele, surpreendentemente, compara Proust ao fundador da
* (BENJAMIN, Walter. Magia e técnica, arte e política: ensaios sobre literatura e história da cultura. São Paulo: Brasiliense, 1994: 47; BENJAMIN, Walter. Gesammelte Schriften II.1. Rolf Tiedemann e Hermann Schweppenhäuser (org.). Frankfurt: Suhrkamp, 1991: 322.)

* (BENJAMIN, Walter. Magia e técnica, arte e política: ensaios sobre literatura e história da cultura. São Paulo: Brasiliense, 1994: 46; BENJAMIN, Walter. Gesamme/ te Schriften II.1. Rolf Tiedemann e Hermann Schwep penhäuser (org.). Frankfurt: Suhrkamp, 1991: 320.)

* (BENJAMIN, Walter. Magia e técnica, arte e política ensaios sobre literatura e história da cultura. São Paulo: Brasiliense, 1994: 47; BENJAMIN, Walter. Gesammelte Schriften II.1. Rolf Tiedemann e Hermann Schweppenhäuser (org.). Frankfurt: Suhrkamp, 1991: 322. . 
* (BENJAMIN, Walter. Magia e técnica, arte e política: ensaios sobre literatura e história da cultura. São Paulo: Brasiliense, 1994: 46.)

* (BENJAMIN, Walter. Magia e técnica, arte e política : ensaios sobre literatura e história da cultura. São Paulo: Brasiliense, 1994: 36; BENJAMIN, Walter. Gesammelte Schriften II.1. Rolf Tiedemann e Hermann Schweppenhäuser (org.). Frankfurt: Suhrkamp, 1991: 310.)
Companhia de Jesus, Inácio de Loyola: "Dificilmente terá havido na literatura ocidental uma tentativa mais radical de autoabsorção, desde os exercícios espirituais de Santo Inácio de Loyola”** Se há uma condenação do modo de vida burguês, com seu puritanismo cristão, Benjamin não demonstra nenhum indício de o confundir com os místicos e ascetas propriamente ditos. Por isso a palavra "Selbstversenkung" não só aparece nesse momento, como também logo na primeira frase do ensaio, que se refere na "síntese impossível" da obra de Proust, que inclui, além da "arte do prosador, a verve do autor satírico, o saber do erudito", "a absorção do místico" ("die Versenkung des Mystikers").*

Agora é preciso digerir a declaração do ensaista para discernir em que sentido se está valorizando o místico, dando o exemplo de Inácio de Loyola. Ele está movido, desde o início, por um explícito entusiasmo pela obra do memorialista francês, e não poupa palavras para alçá-lo às alturas. Dentre os elogios apresentados, consta Proust ter qualidades de um místico. Ser místico é para Benjamin, nesse texto, louvável, e Proust o é, mas de um estranho modo, um modo moderno. Sobrevém a pergunta: Proust é um místico, ou um asceta, moderno?

E o que vem a ser isso? Um escritor que não se dobra ao mero consolo e para buscar a felicidade impossível mobiliza uma rigorosa disciplina de simultânea imersão nos recônditos embriagadores da alma e lúcida presença de espírito para submetê-lo à pesquisa. A ousadia e o rigor proustianos de "autoabsorção" possuem raízes nos exercícios espirituais de Loyola, e mais: ele é o proeminente atualizador desse tipo de busca do Graal em paragens do espírito.

Certamente não há em Proust a sistematicidade doutrinal, propriamente ascética, dos Exercícios espirituais, com seus parágrafos numerados, programa semanal e diário, métodos específicos de contemplação, exame de consciência, visualização, correção do comportamento em ação e pensamento, muito menos o propósito corretivo de um instrutor de almas. Tudo o que em Inácio toma um direcionamento repressivo (aos olhos modernos, bem entendido), dicotômico (bom e mau pensamento, pecados e virtudes), em Proust toma a forma de uma liberação da associação de rememorações. Posto isso, a comparação de Benjamin, no entanto, leva-nos muito além de uma oposição entre um santo canonizado repressor e um artista subversivo. O que há de mais produtivo a retirar daí é que em ambos aparece uma extrema disciplina ascética concen- 
trada na execução de uma realização espiritual. Aqui introduzimonos no cerne do problema que estamos examinando: a correlação entre atividade artística e atividade religiosa.

A comparação de Benjamin não é inteiramente feliz: ela peca pelo desejo laudatório a Proust, que, em geral, é o ponto fraco de seu ensaio. Ele sugere que Loyola foi o último grande escritor a propor uma absorção espiritual radical, e, depois dele, só Proust. O que vale esclarecer é o fato de que Benjamin está, implicitamente, referindo-se ao fenômeno histórico estrito da mística na aurora da modernidade. Segundo o seu conhecimento, Loyola é, de acordo com a tradição, aquele que foi mais longe no estabelecimento de exercícios espirituais programáticos, dentro do cristianismo. Mas existem outras formas de "autoabsorção", e, se Proust é seu representante moderno, então deveríamos citar, dentro das referências místicas, Jakob Böhme, Swedenborg e outros, e, nas referências literárias, quase todos os escritores modernos que se inspiraram em tradições místicas, isto é, grande parte dos escritores modernos mais representativos, ${ }^{*}$ pois mesmo aqueles que não comprovam uma leitura explícita da mística estão plenos de uma recriação de atividades espirituais dentro de um contexto moderno.

Uma vez feita a correção ao entusiasmo do crítico, de fato, a radicalidade da Recherche se coloca par a par com a dos Exercícios espirituais. Cabe então pensar em que sentido se dá essa qualidade comum, em que ela se diferencia em cada caso e quais as implicações teóricas dessa afirmação. Podemos agora nos permitir diferenciar dois tipos de ascese: uma ascese vulgar, burguesa ou sacerdotal, cujo desígnio não é outro senão repressor, resignado, masoquista e privativo; e uma ascese mística, cujo intento é a realização de experiências extáticas e um aprimoramento espiritual integral. $\mathrm{Na}$ história da mística, não podemos dizer que essas duas asceses estejam separadas. Se os místicos foram, sem dúvida, precursores dos artistas no questionamento do moralismo sacerdotal, por outro lado, eles ainda não eram figuras que se assumiam fora da instituição, da fé, muito menos fora da moral. Há na ascese mística cristã muito autossacrifício privativo. Porém, ao contrário do mandamento sacerdotal ao mero fiel, que visa à prática obediente do povo e da burguesia, toda autopunição mística quer chegar ao gozo espiritual, enquanto que a repressão burguesa puritana só quer chegar a ser exemplo de virtude para os outros e forma de salvação pessoal
* (GRUBER, Bettina. Erfahrung und System: Mystik und Esoterik in der Literatur der Moderne. Opladen: Westdeutscher, 1997: 13-16.) 
* (LOYOLA, San Ignacio de. Obras completas. Madrid: Biblioteca de Autores Cristianos, 1963: 249.)

* (BENJAMIN, Walter. Magia e técnica, arte e política: ensaios sobre literatura e história da cultura. São Paulo: Brasiliense, 1994: 47.)

* (Ibidem: 39.)

*(Idem. $)$ depois da morte, que, de um ponto de vista materialista, sabemos que é puramente ilusória.

No caso de uma ascese mística transfigurada pela literatura moderna, o processo de separação dos princípios da ascese vulgar se completa. $\mathrm{O}$ rigor ascético não recai mais sobre a repressão, como forma de aprimoramento moral, mas sobre a percepção temporal, como forma de aprimoramento estético da percepção. Se no místico medieval os dois ainda estão um pouco indistintos - como no caso de santa Teresa D’Ávila e Inácio de Loyola, por exemplo, ainda que em alguns o lado repressor e moralista pouco apareça, como em Eckhart -, no caso do artista moderno, a ascese mesma se "purga" de seu sacrifício inútil e atormentado.

O primor do resultado estético textual quer se tornar o acesso a uma experiência embriagadora e reveladora, e não ser nada além de boa literatura, o que não quer ser menos do que a busca da felicidade. É preciso que a literatura seja o espaço de uma ascese da escrita que pretende, no exercício do escrever, na manipulação das virtualidades da linguagem interligadas às virtualidades da percepção, transfigurar o vivido, abrir as portas da percepção com as chaves da linguagem, que descobrem outras formas de mobilizar as faculdades mentais. Se os exercícios espirituais de Loyola são práticas de visualização e reflexão, os exercícios de Proust são práticas de escrita da rememoração, que mobilizam sensações adormecidas do passado e dão acesso à floresta encantada das associações. Loyola pratica uma visualização de cenas da narrativa cristã, que leva ao uso sacralizado da imaginação, a interiorizar a vida de Cristo.* Proust pratica uma imersão na narrativa vivida pessoal, que ressuscita o potencial adormecido associativo, acorda a imaginação como se acordasse nossa infância esquecida. Por isso afirma Benjamin: "Proust, essa velha criança, profundamente fatigado, deixou-se cair no seio da natureza não para sugar seu leite, mas para sonhar, embalado com as batidas do seu coração".* $\mathrm{O}$ "culto apaixonado da semelhança"* quer retornar à atmosfera onírica infantil. A ascese da escrita é o esforço extremo de cultivo da lucidez para colher o fruto de um sonho realizado pela imaginação, é a construção de uma longa ponte entre o mundo desencantado e a infância perdida: "a ponte para o sonho".* O que a ascese da rememoração descobre é que a criança em nós não está morta, só foi dopada e jogada de lado por uma mistura de frustrações traumáticas, isto é, por um trabalho de desencantamento e um adormecimento da 
capacidade associativa - a má fé da preguiça na mobilização de faculdades ligadas ao prazer lúdico, a deprimente preguiça, promovida pelos estímulos fáceis da vida moderna, de fazer o esforço necessário para sentir prazer.

No ensaio sobre Kafka, Benjamin esclarece melhor que tipo de renúncia é necessária diante dos gozos disponíveis pelos choques audiovisuais. $\mathrm{O}$ gosto pelo esforço da ascese literária vem de um estado de desgosto fundamental, que leva a considerar a inércia sempre pior que o trabalho. A atividade interior vem de uma resposta à insatisfação incessante com o mundo, representada seja pelo pecado original, seja pelo pai culpabilizador, seja pelo aparelho burocrático, seja, inclusive, pela "profunda alienação dos homens entre si" devido ao "cinema" e ao "gramofone".* As mídias mediatizam falseando o imediato, dando um falso alívio ao peso da autoridade. $\mathrm{E}$ o distanciamento da imediatidade, travestido de prazer imediato criado pelas novas mídias, é precisamente o que "obriga ao estudo", ${ }^{*}$ isto é, torna o trabalho ascético em torno da mediação ainda mais necessário do que outrora já fora. A falsa facilitação das mídias e a superabundância de dificultação da burocracia são os dois lados da mesma moeda: impedem a autonomia do indivíduo. Porém, se o mundo permite a um asceta moderno devotar-se à sua faculdade, quando a realidade dá uma "trégua" e não inventa novas formas de estender o espaço da insatisfação fundamental, aparece a chance de "poder ser o que se é". Abandonam-se de bom grado gozos previamente manipulados para bastar-se com a pobreza de um simples estado de espírito presente.

O escritor devota-se ao pormenor para melhor atingir a complexidade do geral, como dizia Adorno. O que devemos insistir aqui é que, para carregar a minúcia de riqueza de sentido, o exercício do núcleo de toda ascese, assim como de toda arte, não deve ser outro senão a concentração. Essa é a condução necessária para cuidar do que há de mais sagrado: a faculdade proustiana de produzir correspondências rememorativas. É uma atenção aberta à imagem imprevisível, uma atenção que não se fecha unilateralmente, mas, ao se manter receptiva ao indeterminado, abarca algo do todo ao determinar-se. O esforço de a atenção individual abarcar tudo e todos retoma a conexão, levantada no início, entre a exercício espiritual individual e a sociedade. 
* (BENJAMIN, Walter. Magia e técnica, arte e política: ensaios sobre literatura e história da cultura. São Paulo: Brasiliense, 1994: 227.) *(Idem.)

* (BENJAMIN, Walter. Rua de mão única. São Paulo: Brasiliense, 1987: 30.)

\section{Realização individual e social}

Não se avança no desejo de uma redenção coletiva se não há dedicação exaustiva à felicidade individual, já que, para dar uma boa contribuição à sociedade, é imprescindível o estudo de si mesmo e isso implica, em primeiro lugar, em dar voz aos seus desejos. $\mathrm{O}$ imperativo de revolução, por mais desligado que esteja do stalinismo e do "marxismo científico", tem sempre a tendência de querer empurrar a justiça e a felicidade para frente, mas elas só se revelam se, ao retrocedermos, damos espaço em nós mesmos para que elas surjam. Retroceder, aqui, não é diferente do despreendimento e esvaziamento interior dos místicos, em especial de Eckhart.

$\mathrm{O}$ freio de emergência do progresso acionado pela ascese individual fica mais explícito na tese $\mathrm{X}$ : "Os temas que as regras do claustro impunham à meditação dos monges tinham como função desviá-los do mundo e das suas pompas. Nossas reflexôes partem de uma preocupação semelhante".* Para pensar como é necessário recusar a "fé no progresso, sua confiança no 'apoio das massas' dos políticos e, finalmente, sua subordinação servil a um aparelho incontrolável", ${ }^{*}$ não lhe vem outra imagem senão as técnicas de meditação dos monges. Aqui se esclarece por que Benjamin comparou Proust à Loyola: ele tem em mente como que o princípio dos exercícios espirituais, devidamente secularizado, é condição sine qua non para o distanciamento do progresso, das massas e do sistema. Em Rua de mão única, Benjamin pondera que a "plebe está possuída por aquele ódio frenético contra a vida espiritual”, * que ela não será aliada de sua própria emancipação se não for educada para isso. Estudo de si e agitação das massas são, portanto, velhos inimigos. A dificuldade está precisamente no fato de todo o Ocidente ter privilegiado um conceito de práxis que está sempre direcionado à eficácia e à ação política e ter esquecido sua dimensão individual e espiritual. Por isso, diminui-se o potencial da realização pessoal a favor sempre da realização coletiva, embora não seja possível contornar o fato de que a realização coletiva depende do trabalho individual de cada um. Mesmo havendo interdependência mútua dos dois fatores, um deles é sempre esquecido ou desprezado.

De fato, esse é um esquecimento frequente de toda a filosofia ocidental, que tem muita dificuldade de pensar a especificidade da prática espiritual, e limita o conceito de prática à política, ou de ação ao puro pensamento, ao logos, isto é, ao plano intelectual e não 
ao plano da experiência interior. A mística especulativa, desde Plotino, pensou, contudo, uma ação espiritual para além do logos. Se ela é contemplação, não se pode esquecer que contemplação aqui não é ausência de ação, é uma dialética complexa de atividade e passividade, em que a entrega do eu na embriaguez espiritual exige extremo esforço ativo e fortalece, em seguida, o sujeito, em vez de enfraquecê-lo, como ocorre na massa. É dessa mesma mística da ação contemplativa que decorrerá a aniquilação do eu no fluxo da linguagem, na poesia moderna.

\section{Ascese da escrita em Benjamin}

Não nos interessa a biografia de Benjamin, neste trabalho, para pensar como ele praticaria um estudo ascético de si, pois o que vale, a nosso ver, é o potencial do escrito sobre a vida, e não a reprodução da vida no escrito. Em outras palavras, mais vale extrair dos seus escritos o potencial de transformação do que tomar sua vida como modelo. Por isso, interessa-nos o que ele escreveu sobre a condução da prática de si por trás de sua leitura dos escritores modernos. Para finalizar, vejamos o que dois de seus mais interessantes amigos filósofos escreveram sobre ele. Vejamos, primeiro, como Adorno o caracteriza.

A pessoa de Walter Benjamin foi desde o ínício uma espécie de meio de sua própria obra, tinha ele tanto a felicidade/sorte (Glück) em seu espírito que o que se chama sempre, em outras circunstâncias, imediatidade da vida, foi rompido. Sem que tivesse sido ascético, pertencia a ele algo de quase incorpóreo, como se somente em sua aparição isso tivesse se efetuado. Seu eu era poderoso como em poucos, parecia estrangeiro de sua própria physis.*

Adorno nega o ascetismo em Benjamin da mesma forma que Benjamin negou em Proust: se for para entender ascese como uma renúncia resignada ao mundo, então não há ascese, e sabemos que boa parte da ascese cristã é feita de puro masoquismo. Contudo, Adorno nega para depois melhor pintar o que não seria uma ascese vulgar e, a nosso ver, termina por nos dar um bom quadro do que são qualidades ascéticas emancipatórias. Benjamin não compactuava com os imperativos da imediatidade. Ele sabia, devido a um dom raro pessoal, distanciar-se da materialidade para melhor experimentá-la. Essa é a questão: não é o caso de negar o corpo e as coisas, mas de, ao saber destacar-se de suas limitações, das limita-
* (BENJAMIN, Walter. Briefe I. Theodor W. Adorno e Gershom Scholem (org.). Frankfurt: Suhrkamp, 1978: 14.) 
* (SCHOLEM, Gerschom. Walter Benjamin: a história de uma amizade. São Paulo: Perspectiva, 1989: 62.) ções que eles nos impõem, libertar-se das mesmas para usufruí-las melhor. $\mathrm{O}$ próprio Adorno diria que tal problemática está inserida na dialética de dominação entre o homem e a natureza no âmbito da interioridade. Os filósofos gregos e os monges cristãos queriam dominar seus impulsos. Hoje, entretanto, os impulsos estão conduzidos pela abstração do capital, por meio da indústria cultural e de consumo, o que aumenta a necessidade não do controle da consciência, que é uma psicologia pré-moderna de repressão, mas de cuidado com toda uma dimensão inconsciente ignorada, cuidado que só pode ser praticado pela ação a um só tempo consciente e distraída, uma atenção flutuante que não deixa de ter suas raízes nas práticas contemplativas dos místicos, lembrando que ele é tanto racional quanto poético. Praticar a atenção consciente ao inconsciente, atenção espiritual à corporalidade: eis o que os princípios da ascese antiga não nos ensinaram a fazer. Porém, mesmo essa tarefa não pode prescindir de seu legado. Ao prestar atenção ao corpo, é preciso treinar a própria atenção. Isso é algo que o apelo às massas está cada vez mais minando. De diferentes maneiras, Benjamin, Adorno e Foucault sugerem que a psicanálise teria muito a ganhar com uma busca genealógica de suas práticas analíticas na mística; e a mística ganharia muito se se esforçasse por se atualizar a partir da psicanálise e da crítica social freudo-marxista.

Gerschom Scholem nos permite concluir nossas consideraçôes com mais um dado do modo de ser de Benjamin.

Havia nele um elemento de pureza e de incondicionalidade, uma devoção ao espiritual, como pode existir num escriba que é jogado num mundo diferente e partiu em busca de sua "escrita".*

Comprovando a potencialidade espiritual que já vimos em Adorno, Scholem propõe uma comparação curiosa com um escriba que, jogado num mundo diferente do seu, partiu em busca de desenvolver o "seu" mundo em meio à estrangeiridade. No mundo moderno, numa sociedade que privilegia o conhecimento, isso é possível através da escrita. $\mathrm{O}$ exercício da escrita configura uma ascese de escritor. Partir em busca da escrita não é nada diferente de buscar a felicidade, o que se sublinha agora é o meio, e não o fim. Para tomar distância do imediato, deve-se exercitar no âmbito da mediação que escrita faz entre o eu e o mundo.

Por isso mesmo, uma prática da escrita não se diferencia de uma atividade da leitura. $\mathrm{O}$ exercício da escrita torna possível a lei- 
tura do mundo, é no seu espaço silencioso, na ruptura com a imediatidade, que a leitura de seus enigmas se principia. Na leitura de textos literários modernos decisivos, frutos de uma busca existencial vigorosa e doentia, o escriba moderno que foi Benjamin fez do exercício crítico um desdobramento esclarecedor dos enigmáticos exercícios espirituais proustianos. Ainda assim, se procuramos aqui destrinchar alguns mistérios que sua escrita perpetuou das leituras, resta ao leitor fazer de nossa passagem e resguardo dos impenetráveis segredos benjaminianos um convite ao exercício que fará da leitura a experiência.

Eduardo Guerreiro Brito Losso é professor adjunto de Teoria da Literatura da UFRRJ. Cursou doutorado sanduíche na UFRJ/Universität Leipzig em ciência da e fez pós-doutorado na UERJ. Foi um dos organizadores do livro Diferencia minoritaria en Latinoamérica/Diferença minoritária na América Latina, pela editora alemã Georg Olms, de 2008 e do livro O carnaval carioca de Mario de Andrade, pela editora Azougue, de 2011. E-mail: <edugbl@msn.com>. 